\title{
Models and Tools for Research of Innovation Processes
}

\author{
Bogoviz, A. ${ }^{1} \&$ Mezhov S. ${ }^{2}$ \\ ${ }^{1}$ Doctor of Economics, Professor of National Research University Higher School of Economics (HSE), Moscow, \\ Russia \\ ${ }^{2}$ Head of the Department «Regional Economy and State and Municipal Management» of Altai Academy of \\ Economics and Law, Barnaul, Russia \\ Correspondence: Bogoviz, A., Doctor of Economics, Professor of \\ National Research University Higher School of Economics (HSE)， 101000， Moscow， Russia. E-mail: \\ abogoviz@hse.ru
}

Received: October 24, 2014

Accepted: November 7, $2014 \quad$ Online Published: January 11, 2015

doi:10.5539/mas.v9n3p159

URL: http://dx.doi.org/10.5539/mas.v9n3p159

\begin{abstract}
Modern production and innovation processes in industrial corporations differ by complex nature of modern technologies and organizational solutions. Adequate methodological approaches to their analysis and evaluation of efficiency are required. The present study contains the concept and the model of operational and innovation program for which formulated theoretical and methodological principles and systematic statement of the general problem of planning, designed to optimize the process of resource usage under different criteria, including: investment, financial, technological, industrial and information capabilities of the corporation.
\end{abstract}

Keywords: operational and innovation processes of the corporation, the production program of the industrial corporation, innovations, product life cycle, modeling

\section{Introduction}

It is not a secret that the issues of building an innovative economy are still difficult to study as at the present time observed a violation of systemic organizational development principles, proportions and balance between the internal and external environment, there is virtually no theoretical and methodological framework for solving such problems, while the successful experience of western corporations is not available for Russian enterprises.

Innovations, as a basis for organizational development and competitiveness of the enterprise, require constant investments, the sources of which are in the area of operating activity and certainly have a significant impact on its effectiveness. The reduction in current financing worsens profitability and efficiency ratiosin the reporting period, the decrease in financing of innovationsharms strategic effectiveness of the corporation.

In varying degrees of completeness, this problem is solved in most western corporations which successfully combine the tactical and strategic aspects of the activity.

It must be emphasized that at the present time there is a certain contradiction between the scope of theoretical and applied research on the formation of the methods and mechanisms to improve the management of modern corporations and the lack of innovative corporations in the Russian economy.

On the basis of above-mentioned it can be concluded that the scientific problem, connected with the development of methodology for planning the operational and innovation activities of modern industrial corporations, is considered extremely important. It appears that the solution of this problem shall provide a set of methods and tools for better planning of operational and innovation processes and evaluate the effectiveness of investments in innovation projects with due regard to innovative capacity of the enterprise.

\section{Methods}

Methodological aspect of knowledge of the system or the process involves the construction of a more or less adequate model allowing to significantly expand the range of research and get the structural, historical, logical and functional data, which for various reasons are not available during the direct study of the object. In addition, these data are necessary for the constructive solution to the organizational and managerial problems of corporate governance, in particular related to innovations. 
In order to solve scientific problems indicated in the present study used a systemic methodology, which allows to rely on different approaches and concepts in forming the models of the object. The economic-mathematical methods and models, including methods of correlation, regression, factor analysis, methods of expert assessments and others are also used.

The data of Russian Federal Service of State Statistics, laws and regulations of the Russian Federation, as well as corporate reports of innovative companies were used as information sources to this study. The data processing involved the use of the statistical packages and spreadsheets.

\section{Results}

The main new scientific results are the following programs significant for the development of science and practice:

1. The methodological approach to corporation planning that develops existing approaches on the basis of a set of optimization and simulation models, taking into account the balance of operational and innovation processes based on formal criteria. In contrast to existing approaches (Pleshinsky, 2004; Sobolev, 2000; Titov, \& Mezhov, 2013; Titov, 2007; Danilin, 2006) the production program is complemented by the optimal strategy for implementation of a new product, as well as evaluation of investment strategies and changes of innovative capacity of the enterprise.

2. The model of planning of the operational and innovation program iteratively generates many optimization options, implementing the demand forecast based on the life cycles using the simulation model. It also complements and develops existing approaches to the planning of the production program (Sobolev, 2000; Titov, \& Mezhov, 2013; Danilin, 2006) by way that this model is implemented in a dynamic form, explicitly takes into account the time factor and the set of transformation strategies of innovation potential.

\section{Discussion}

The formulation of tasks of the planning process of the operational and innovation program of the industrial corporation.

Any strong corporation can only be viewed from the standpoint of the unity of the operational and innovation activity.

The enterprise finances the production activity for each business process $\left(\mathrm{E}_{\mathrm{i}} \rightarrow \mathrm{BP}_{\mathrm{i}}\right)$, requires the necessary resources $\left(R_{1}, \ldots, R_{n}\right)$, processing some of them, produces the output equal to $\left(X_{1}, \ldots, X_{n}\right)$. Then the enterprise sells it and receives an income, the part of which is intended for the formation of investment sources. From these sources formed a capital for financing the operational activity $\left(I_{0}\right)$, i.e. for restoring $E_{1}, \ldots E_{\Pi}$ and financing the innovations $\left(\mathrm{I}_{\mathrm{n}}\right)$. Raising debt capital in the event of the owned capital is not excluded. Thus, the total invested capital can be determined as $\mathrm{I}=\mathrm{I}_{\mathrm{o}}+\mathrm{I}_{\mathrm{n}}$.

According to our research, there are several approaches and tasks, interdependent by these approaches, that are most consistently studied by many authors.

Separate economic and mathematical models or their groups (systems) for the development of advanced, current and operational schedules and production programs, are currently developed, experimentally tested and partially implemented into planning practice of operational and innovation processes in companies.

Most of the considered models of prospective and current planning in the mathematical sense are considered as problems of mathematical programming. In planning practice making decisions is usually based on the need to achieve multiple targets, i.e. the solution is to be evaluated simultaneously according to several criteria, but the canonical formulation of tasks of mathematical programming requires a one-criterion approach, that certainly limits its extensive use in the planning practice.

A rather constructive approach to forecasting the production programs of the corporation development on the basis of economic-mathematical tools is a system of optimization, partly integer models, widely described in the works (Pleschinsky, 2004; Sobolev, 2000; Titov, \& Mezhov, 2013; Titov, 2007). In these models considered only part of the product life cycle related to the production and sale of products, business and financial processesare widely represented, but there is no planning process of research and development of new products, technologies (R\&D).

One more constructive approach to the planning process of production programs of enterprises in terms of innovations on the basis of economic and mathematical models is an approach developed in the works of (Danilin, 2006). As is known, the frequency of stages of development, pre-production, release and use of the product since the stage of theoretical studies and prior to removing the product from the production is called the 
product lifecycle. In other words this is the period from the design of a product to the termination of its sales. In the product life cycle it can be indicated the following consolidated stages: research scientific work, design and experimental preparation, process-layout preparation, the launch of a preproduction run, the production growth, stabilization of production volumes, the decline in the product production and phase-out.

According to these approaches, modeling allows to determine an expected year of the launch of a new product, taking into account the economic conditions of production for the company as a whole. A demand for products of each type, sales volume, net total cash flow with due regard to savings for each year, the complexity of the program and other factors are used as restrictions; maximizing the net present (current) value and other factors are used as a criterion. The forecast based on the optimization models can be represented as a single-point discrete process in which the parameters of the environment require the special evaluation.

The present studies (Mezhov, 2012; Mezhov, 2011; Mezhov, 2014) show that such a formulation of the problem is noturgent for today's most advanced corporations. The works (Bogoviz, \& Mezhov, 2014; Kondratyev, 2003; Prahalad, 1996; Chesbrough, et al., 2006; Boutellier, R., et al., 2008; Gassmann, 2006) show that the replacement of products in the production program is entirely dictated by the market demand and the principles of business competition. However, the model scheme of product life cycles remains an important methodological promise to build a comprehensive operational and innovation program. We shall discuss it further.

Existing models and tools used for the planning do not provide the solution of a number of key tasks, such as:

1. Planning of the early stages of the innovation process;

2. Determination of the investment volume under the selected innovation project (or they are given as an exogenous parameter);

3. The full product life cycles are not taken into account.

According to our research, the most immanent method can be the imitation modeling combined with optimization modeling.

Further we define the methodological principles of description of planning of the program for the production of the modern corporation, represented a synthesis of resource capabilities, limitations of the production and innovation capacity.

In an instrumental relation the task of formation of such a program shall be based on optimization models, that is natural when optimizing the resource utilization, on forecasting models, as occur the cash flow forecast and a number of characteristics for investment appraisal, and on imitation models, which are necessary for the assessment of options for planning of production, sales and investment policies.

Assumptions and basic conceptual distinctions of the proposed formulation of the task from the conventional approaches to planning of production and sales plans:

1. A market enterprise independently decides on all matters of innovation policy on the basis of the entrepreneurial initiative.

2. An enterprise has the ability to carry out $\mathrm{R} \& \mathrm{D}$ and introduction of new products on the basis of its own innovative capacity.

3. An enterprise carries out research and development of new products on a regular basis, rather than on the basis of discrete projects adopted at the time of the product start-up, i.e. provides the whole range of search and research works, including the scheme of open innovations (it integrates with partners), optimizing investments between the production and innovations.

4. The units being planned have all the necessary competencies and knowledge of the main trends of development of the industry, therefore, well ahead of the product launch determined the perspective concepts that are further brought to production. Concepts of the products brought to the innovation process are considered as accepted projects that consistently brought to production and sales.

5. The total investment volume aimed at complete development of a new product shall be recovered through sale and bring the industry average profit and rent in accordance with the strategic plan of the corporation.

6. It is obvious that the requirement to the specified payback is entirely due to the innovative potential of enterprises and suggests its account in the formal procedures for evaluating the effectiveness of investments allocated in innovations.

7. Since the concept of evaluating the effectiveness and payback of the investments (NPV) requires 
forecasting the cash flows on a sufficiently long time interval, then itshall necessarily be reflected in the general model of the program formation.

8. The innovative potential of an enterprise affects the effectiveness of in-vestments, therefore, it is necessary to take this fact into account in the traditional procedures for evaluating the investments.

9. Since the main trends of the production of each product are specified by the product life cycles, while the output also depends on the demand, actually the life cycle curve defines an average statistical trajectory, around which varies the value of the random variable of the "demand" for the product for each year, statistically obeying the life cycle curve.

10. Taking into account the fact that the market power of any corporation is determined by the market share, the sales plan shall be guided by the maximum output of products with limited resources.

In the framework of the operational and innovation program the following tasks shall be solved:

1. Implementation of economically justified demand and sales forecast.

2. Forecasting the dynamics of prices of final products and production factors.

3. Analysis of the possible sources of capital raising and assessment of financial risk.

4. Construction of the model of the industry development: trends of technologies, products, general organization of industrial markets, raw material prices.

5. Formation of a regulatory framework for planning as the basis for optimization and control of corporate expenses and prime costs.

6. Formation of the systems of life cycles of products and technologies.

7. Linking the approaches of production, financial and investment planning into a single complex on the basis of the project approach.

8. Development of optimization criteria and levels of criteria-based standards of balancing the plan options in a dynamic setting.

9. Formation of a formal program strategy for implementation of innovation solution: the duration of the stages of the innovation process, tactics of stages financing, tactics of products launch, marketing tactics, including the methods of promotion and pricing. (For instance, see (Cooper \& Edgett, 2006)).

10. Determination of the total volume of investing the program and proportions of financing the industrial and innovative parts.

11. The calculation of the optimal growth rate of the corporation within the framework of the sustainable financial state.

We propose to solve these tasks using models, system methods, including imitation and optimization modeling that shall allow to reveal the quantitative interaction of investments, innovations, sources of funding, that can lead to making well-founded strategic decisions (Mezhov, et al., 2014).

The purpose and nature of the model of planning the production of products in conditions of constant investment spent on innovations can be stated as follows.

Knowing the forecast production cycle of each product: the dynamics of output and sales volume in volume terms, production costs, labor intensity, etc. on intervals of the pro forma cycle, the volume and pace of investment and possible intervals of timing of the products launch, current and strategic development indicators, it is necessary to define such terms of the launch of new products in order to perform the tasks in terms of growth of the value of the corporation, provide the main economic and financial indicators of effectiveness and sustainability with the resources allocated to the corporate budget, including borrowed capital. At the same time it is necessary to determine the optimal volume of innovation investment, observing, on the one hand, the balance between profitability and liquidity, on the other hand, the optimal duration of the start of sales of new products, in order to maximize rents from possessing unique expertise.

Optimal volumes of innovation financing are defined by strategies for R \& D implementation. These strategies are considered as logically related, consistent volumes of investment of each stage of the innovation process, as well as the rate of work production and release of new products onto the market. At the same time there occurs the following dilemma: the acceleration of the innovation process requires large amounts of funding, that definitely reduces the current performance of the corporation, but early marketing of new products shall provide an additional income in the form of Schumpeterian rents. In the framework of operational and innovation 
program (OIP) the task of balancing the volume, rate and payback of innovation investment shall be solved.

\section{Description of the Subject Area}

An industrial corporation has a high potential for innovations, on a regular basis it manufactures, sells products with known product life cycles (projected market demand) and carries out the research to develop new advanced products and technologies.

The integral numerical value of innovation potential can be determined by the expert-analytical methods, for example, by the method of analysis of hierarchies. From our point of view, an expected potential is due to the high level of organization and management.

In the framework of the strategic plan for solution of various problems the corporation allocates a certain investment volume $I$, which is specified in the tactical plan created for solution of the current tasks. $t$ indicates the number of periods which a tactical plan is formed for, containing production and innovation component, $I_{t}$ indicates the investment volume allocated to this plan. Then:

$$
I=\sum_{t=1}^{T} I_{t},
$$

where $T$ is the number of the planning periods (years).

In turn, the volume of the current investment may consist of internal and borrowed funds. In this case, we assume that the borrowed funds are used only to finance current operations, financing of innovation is carried out at the expense of internal funds, major investments in upgrading technology for new products can be carried out at the expense of internal funds and long-term loans. The total amount of borrowed funds shall not violate the requirement of financial stability and the capital structure of the corporation, i.e.

$$
k_{s}=\frac{K_{b}}{K_{s t d}} \leq k_{\text {nor }},
$$

where $k_{s}$ - the coefficient of the capital structure; $K_{b}$ - borrowed funds; $K_{\text {int }}$ - internal funds; $k_{s t d}-$ internal standard of the capital structure.

Let the corporation produce $J$ kinds of products, then $x_{j}, j=1,2, \ldots J$, shall be the output of the $j^{\text {th }}$ product.

Let us denote by $\varphi_{n i}$ the set of indices of the products $i, i=1,2, \ldots N$, the set of potential products (development on new products) located in the innovative development, then $I_{n i t}$ investments shall be spent on each designed product, so that:

$$
I_{n t}=\sum_{i=1}^{N} I_{n i t}
$$

After the start of mass production the investment in development of a new product shall be terminated and have only production costs. Capital expenditures for the preparation of a new technology for a new product shall be denoted as $I_{k n}$. Taking into account the fact that the introduction of a new technology is usually carried out before releasing the product into mass production, the dynamics of $\mathrm{R} \& \mathrm{D}$ investment on the time axis shall be as follows (see Figure 1.):

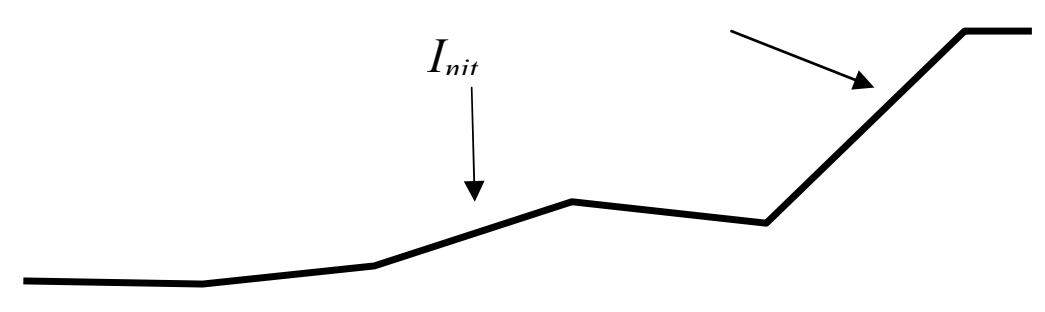

Figure 1. The option for dynamics of financing of in novation project development 
The graph shows the dynamics of investments, $I_{n t}$ means current assets for years, $I_{k n}$ reflects the conditional "oneness in time" of capital expenditures before the widespread production of innovative products. The period of development of the product shall not be considered as it reflects only the expenses and it is not included in the operational program.

In this context, the formation of the model of the production program shall be based on the concept of the product lifecycles. Based on research of retrospective statistics on the economic product life cycles of separate industrial products, and after their appropriate processing with the use of mathematical models appears the possibility to forecast the duration of the production of a new product with an acceptable accuracy, taking into account the time from the time the product is launched till its withdrawal from the market.

We can get the curve of the product life cycle, reflecting the stage of production, if using the method of statistical analysis of forecasting the various technical and economic indicators of production depending on the prevailing trends of output volume by years of the accounting period. In the framework of the present study it should be considered that the product life cycles are determined by the marketing department and are exogenous variables specified by an external source.

We denote the lifecycle of the $j$ product as $G_{j,}, j=1,2, \ldots J$, then $J$ products can have various product life cycles as a continuous time function,

$$
\mathrm{Gj}=\mathrm{Gj}(\mathrm{t})
$$

Or as a discrete, tabular form of a task, in the form of compliance:

$G_{j}^{i}-t_{j}^{i} ; j=1,2 \ldots J ; i=1,2 \ldots \pi, i$ - numbers of time periods, $\pi-$ a number of discrete partitions of the table (a number of years). In general the curve of the product life cycle after the product launch can be presented as follows (see Figure 2):

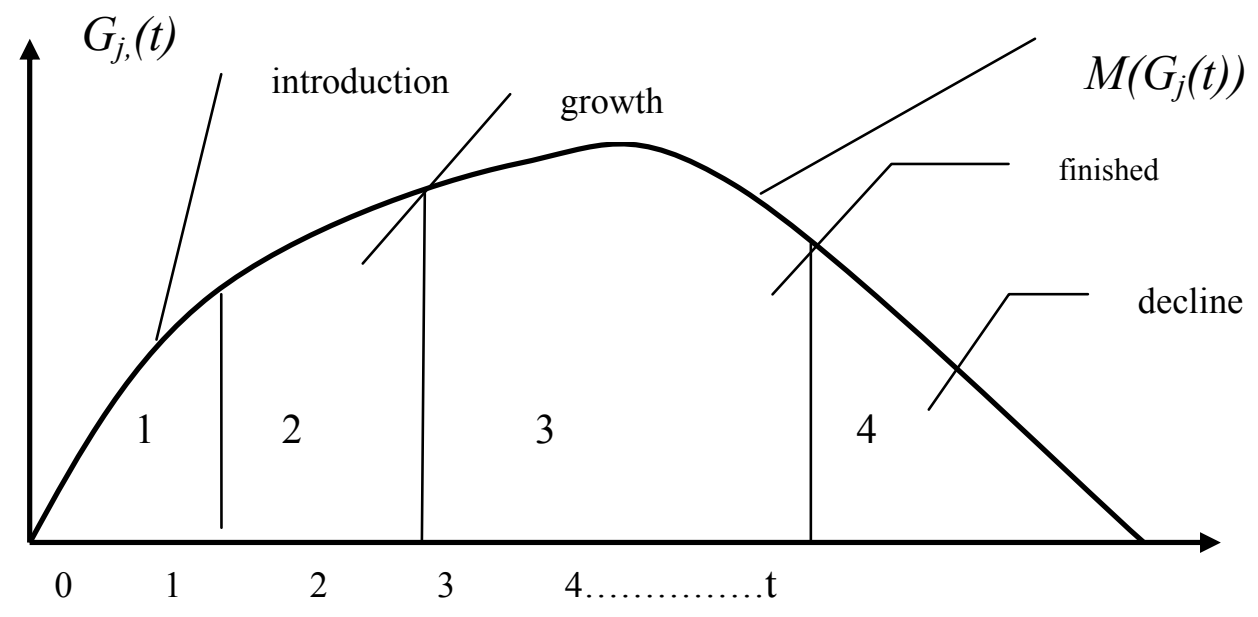

Figure 2. General form of the curve of the product life cycle

In fact it is possible to have both the analytical dependence, for instance, sales volume depends on the time, and a tabular dependence with the corresponding derived indicators, such as income, expenses, etc. All these indicators can be represented both in value and natural forms.

If for the construction of the analytic dependence used regression analysis, the curve $M\left(G_{j}(t)\right)$ shall represent an average value of the fluctuations in sales over time, while in the framework of regression analysis determined the standard deviation of sales $-\sigma_{j}\left(t_{k}\right)$ using Monte Carlo modeling method, where $t_{k}$ means the time of forecasting the volume of demand. Thus, $\sigma_{j}\left(t_{k}\right)$ shall be different for different time intervals, which is natural, since this standard deviation reflects the average spread of demand in different time intervals of forecasting. Obviously, the acceptable value of sales in the planning, according to the law of three sigma, may lie with high probability in the following interval:

$$
M\left(G_{j}(t)\right)-2 \sigma_{j}\left(t_{k}\right) \leq G_{j}(t) \leq M\left(G_{j}(t)\right)+2 \sigma_{j}\left(t_{k}\right)
$$

This interval shows that during modeling it shall be considered the probable deviation of sales volume from its average value (short-term forecast), which is defined by the product life cycle curve (long-term forecast). With a 
steady drop in demand for the product, the separate increase or accelerated decline in sales volume, the management shall not be misleading, since the main trend shall be determined by the curve $M\left(G_{j}(t)\right)$. Such a shape of the curve can be represented by the power polynomial (parabola) in procedures for regression analysis, or in a tabular form, which can be more convenient for practical use in the planning of the program.

In fact, it is possible to form a production program with the use of linear models. However, the features of the subject area, described above, require a few other approaches to the planning.

Recall that, in fact, in the formation of production volume for each product using the model it is necessary to optimize not the volume that we know roughly in the projected life cycle, but the number of important indicators conditioned by the efficient use of available resources with certain interval estimates (equation (1)) of the production volume in volume terms. In this case the optimization makes sense because only the upper limits of volumes are set. There are other problems, namely, within the structure of demand (rolling short-term forecast) and long-term forecasting of product life cycles for each product it should be formed a production program and an innovation investment program, which shall provide the replacement of products, derived from production. Then we can formulate the problem of the OIP formation as follows:

In the presence of available life cycles of all products: $G_{j}=G_{j}(t), j=1,2, \ldots, J$; planning time, or at discrete consideration, specifying the demand forecast (2), it is necessary to find an optimal production schedule in physical indicators at the time $t$ :

$$
\begin{array}{r}
x_{j}^{t} \leq G_{j}^{*}(t) ; x_{j}^{t} \in X_{t} ; t=1,2, \ldots, T ; j=1,2, \ldots, J, \\
x_{j *}^{t}=(1-\alpha) x_{j *}^{t 1} ; x_{n j *}^{t}=\alpha x_{n j *}^{t 1} .
\end{array}
$$

where $X_{t}$ means an optimal plan, $x_{j}^{t}$ means nomenclature plan components, $\alpha$ means a control parameter, the share of new products to replace the old ones, with $\alpha=0$, a new product is not included in the program; when $\alpha=$ 1 , an old product is completely excluded from the program, with $0<\alpha<1$ in the program included both products in the proportions shown in the equation (4); $x_{j *}^{t 1}$ means a product being excluded from the program; $x_{n j *}^{t 1}$ means a new product launched into production; $t_{1}$ means the time of the product replacement.

The complexity of the procedure for determining the optimal plan $X_{t}$ cwith due regard to the mechanism of replacement of an old product onto a new product (4) is conditioned by the need to taken into account the following:

- lifecycles on each product defining the upper limits of the output;

- production capacity that determines the limiting boundaries of the output: if the demand forecast for a product is less than the output capacity on the same product, i.e. $G_{j}(t)<X_{j}^{m}$, then $\mathrm{x}_{j}^{t} \leq G j,(t)$, and if $G j,(t)>X_{j}^{m}$, then $\mathrm{x}_{j}^{t} \leq X_{j}^{m}$, it means that when demand exceeds the capacity, the value of an expected volume does not exceed the capacity, if it does not provide an additional product launch;

- options of the strategy used for replacement of an old product onto new ones, for instance, replacement can be "slow", "fast", "compromise", when for some time both products are included in the plan;

- options of investment with or without an improvement of the innovative capacity, etc.

The sales volume for the period $t$ is determined as follows:

$$
U_{t}=\sum_{j=1}^{J}\left[c_{j} x_{j}+c_{j *}(1-\alpha) x_{j *}^{t 1}+c_{n j *} \alpha x_{n j *}^{t 1}\right]
$$

where $c_{n j *}$ means the price for a new product, $c_{j *}$ means the price for a product excluded from the program, $n j *$ means the index of a new product.

The operational and innovation program shall reflect the growth of the key performance indicators that determine the long-term development of the enterprise, and at the same time its financial stability in the short term. Provision of financial equilibrium in the process of enterprise development is a system of measures aimed at maintaining the mechanism of the balanced growth on basic economic indicators in the long run.

The development model of the enterprise leads us to the issue of financial support of the enterprise's growth. For the growth to be sustainable, the operational and financial policies and growth targets shall be agreed. Such growth is usually expressed in terms of an increase in internal funds.

The work (Higgins, 1998) clearly shows that the achievement of an expected growth rate depends on the applicable financial policies. According to (Higgins, 1998) the growth rate:

$$
g=r_{p r} \times d_{p} \times o_{a} \times k_{e q}
$$

where $r_{p r}$ - profitability of sales, $d_{p}$ - the share of undistributed net profits of the enterprise spent on 
re-investment, $o_{a}$ - asset turnover ratio, $k_{e q}$ - asset/equity ratio (financial leverage).

If the actual growth rate of the corporation exceeds the rate of its sustainable growth, the corporation shall either improve the operating performance (profitab ility of sales and asset turnover ratio), or change the fiscal policy (increase the share of undistributed net profits or financial leverage). Equation (6) specifies the conditions for optimal growth of the assets as a transition from the system of indicators, calculated for the period $t$ to the system of the same indicators calculated for the future periods: $t+1, t+2, t+3 ., \ldots, . T$. Then, using the equation (6) the amount of growth of the company assets (capital) can be calculated.

The Higgins model gives a visual representation of the critical variables (coefficient of profitability, capitalization ratio, financial leverage ratio, asset turnover ratio)determining the company's sustainable growth.

With the imbalance in periods of the growth of internal funds and the sales growth, the model of J. Van Horn (Van Horne, 2009) is proposed. In this case, it is proposed to introduce into the model the initial sales volumes $\mathrm{U}_{0}$, the initial size of the internal funds $K_{c}$, the absolute amount of dividends Div, which the company is planning to pay, as well as the volume of issue of ordinary shares:

$$
s q=\frac{\left(K_{C}+\Delta K_{C}-D i v\right)\left(1+\frac{K_{3}}{K_{C}}\right) \times \frac{U}{A} \times \frac{1}{U_{0}}}{1-\left[r_{u} \times\left(1+\frac{K_{3}}{K_{C}}\right) \times \frac{U}{A}\right]}-1,
$$

where $s q$-the level of attainable growth, $\Delta K_{c}$ - capital increase for the next period.

Within the framework of the adjusted model there can be a significant growth ( $s q$ ) by improving the effectiveness of the work (higher profits) and a higher debt ratio. In this case in order to ensure the growth in the future, it is necessary to increase the debt. The model shows the attainable level of growth year after year, under changing conditions.

The Higgins model is focused on the growth, mainly due to its internal funds, while the J. Van Horn modelis focused on the growth due toborrowed funds. The problems of innovation development of Russian corporations involve high risk and complexity of capital raising, both in the institutional and financial aspects. Therefore, the Higgins model is more suitable for modeling the growth of Russian corporations.

\section{The forecasting model of the production program.}

For the formation of a functional and a system of limitations of the production program in the OIP structure an approach described in the scientific work (Ragulina and Malyshkov, 2014) can be used as an instrumental basis (see Figure 3).

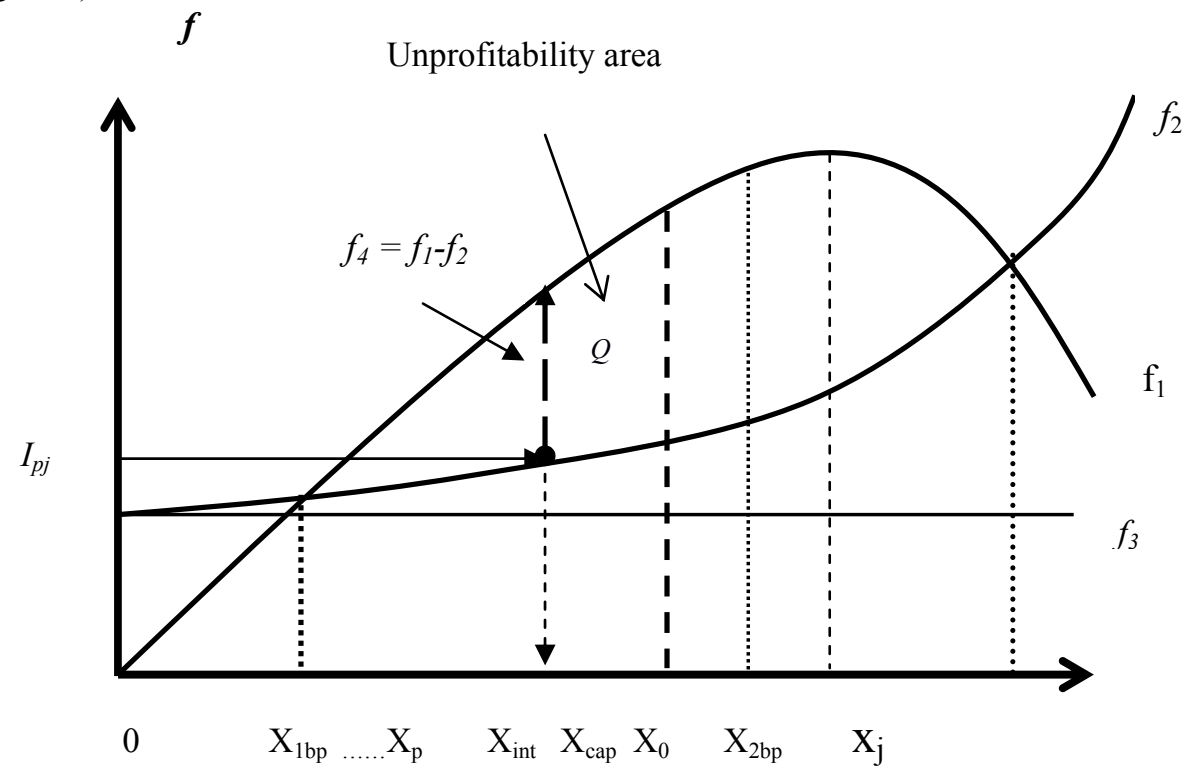

Figure 3. Non-linear model of economic production processes

$f_{1}, f_{2}$ - functions of sales volume and production costs, respectively;

$I_{p j}$ - invested capital (the amount of funds for implementation of the production program);

$f_{4}$ - profit function; $\mathrm{X}_{1 \mathrm{bp},} \mathrm{X}_{2 \mathrm{bp}}-$ breakeven points;

$\mathrm{X}_{\mathrm{p}}$ - production output in actual measurement, corresponding to a given volume of the advanced capital $I_{p j}$; 
$\mathrm{X}_{\mathrm{d}}$ - demand volume in actual measurement; $\mathrm{X}_{\mathrm{cap}}$ - production output, corresponding to the production capacity; $\mathrm{X}_{0}$ - production output in actual measurement, corresponding to the maximum profit under given processing capabilities.

$f_{3}$ - fixed costs $\left(f_{2}=f_{2 \mathrm{p}}+f_{3}\right) ; f_{2 \mathrm{p}}-$ semi-variable costs.

This approach is based on the use of linear or non-linear functionsas modelsof sales and costs, these functions can be constructed on the basis of the regression analysis on retrospective data of the company for a certain period of time. If such functions are constructed for each product, their accumulation can serve as a forecasting model for the production program of the enterprise. At the correct construction of the functions of sales and costs, when the fixed and variable costs are clearly indicated, the interaction of these functions adequately reflects the economic model of the enterprise.

The nature of an actual behavior of the functions of production and costs allows to accurately describe the curves $f_{1}$ and $f_{2}$ using the second order polynomials by the regression analysis in the following form:

$$
\mathrm{Y}=\alpha_{1} \mathrm{x}^{2}+\alpha_{2} \mathrm{x}+\alpha_{3} .
$$

Then, using an appropriate definition of the coefficients, occurs the following equation:

$$
\begin{aligned}
& f_{l}=a_{1} x^{2}+b_{1} x+q_{1}, \\
& f_{2}=a_{2} x^{2}+b_{2} x+q_{2} .
\end{aligned}
$$

In this case the functions of profitability can be found:

$$
f_{4}=\left(a_{1}-a_{2}\right) x^{2}+\left(b_{1}-b_{2}\right) x+\left(q_{1}-q_{2}\right) .
$$

If we define $a_{4}=a_{2}-a_{1} ; b_{4}=b_{2}-b_{1} ; q_{4}=\left(q_{1}-q_{2}\right)$, as $q_{1} \rightarrow 0$, while $q_{2}$ is significantly greater than 0 , as it shows the share of fixed costs (see Fig. 4.3), then $q_{4}<0$ :

then:

$$
f_{4}=a_{4} x^{2}+b_{4} x-q_{4}
$$

Thus an informative (econometric) meaning of the parameters $a_{k}, b_{k}$ and $q_{k}$ areas follows: $a_{1}$-adjustingfactorwithdimensionequal to $\frac{1}{p c s^{2}} ; b_{1}$ - price of a product; $c_{1}$-regressionerror, at the correct presenting of $f_{1}, q_{1} \rightarrow 0 ; a_{2}$ - adjusting factor of dimension costs $\frac{1}{p c s^{2}} ; b_{2}$-variablecostsperunit; $q_{2}$-fixedcostsperunit, at the same time $\sum_{i}^{J} q_{2 i}=s_{c n s t}$, here it is important to emphasize that $s_{c n s t}$ means fixed costs for the whole OIP; $a_{4}$ means adjusting factor of profitability from the production volume with dimension equal to $\frac{1}{p c s^{2}} ; b_{4}-$ account of the fixed costs in the profit calculation.

Then using a non-linear model of the economic production processes, the information obtained using this model, it can be constructed the optimization model of the production program.

The function, objectives, sales volume:

$$
\begin{array}{r}
U_{t}=\sum_{j=1}^{J}\left[c_{j} x_{j}+c_{j *}(1-\alpha) x_{j *}^{t 1}+c_{n j *} \alpha x_{n j *}^{t 1}\right] \rightarrow \max \\
U_{t}=\sum_{j=1}^{J}\left[c_{j}\left(\varphi_{j}, t\right) x_{j}+c_{j *}\left(\varphi_{j *}, t\right)(1-\alpha) x_{j *}^{t 1}+c_{n j *}\left(\varphi_{n j *}, t\right) \alpha x_{n j *}^{t 1}\right] \rightarrow \max ,
\end{array}
$$

where $\varphi_{j}, \varphi_{j *}, \varphi_{n j *}$ are the elements of the set of controls developed by the planning of the corporation group, for improvement of the effectiveness of products sales on the market. The use of controls allows, in particular in the automatic mode, to adjust the prices of products in the objective function. The F set contains the options to adjust the system of constraints of the optimization model and the objective functions in the automatic mode (Mezhov, 2012). The controls are considered as possible sets of prices, technological coefficients of the matrix of restrictions, all possible combinations of aggregation (for example, 12 types of nomenclature positions, the types No. 2, 5, 7 form a restriction on the joint production output, as well as the right parts of the restrictions can change due to changes in separate types of resources or their prices, etc.).

All possible controls $f_{l}$ and $f_{2}$, or deformations, in general, lead to either an increase or a decrease in the area of the break-even work, in particular, the function $f_{l}$ can have the following controls:

- an increase in sales volume due to an increase in output at constant prices;

- an increase in sales volume due to the price increase at a constant volume of production;

- a decrease in sales volume by lowering the prices;

- an increase in sales volume by reducing the price and increasing the demand; 
-changes in sales volume due to minimization of receivables.

Formally all these controls lead to the fact that the initial curve $f_{l}$ is subjected to the deformation by the control operator, i.e.

$$
f_{l} \mathrm{~d}=\varphi f_{1},
$$

where $\varphi$ is a control operator, which can be defined by a constant, function, procedure.

For example, it is necessary to reflect in the model an increase in sales volume by increasing the original price at 1.2 times, therefore, we shall obtain $f_{1} d=1.2 f_{1}$. Or we can suppose there is a situation when an increase in the volume of production changes the sales volume in proportion to the linear function $\mathrm{F}=\varphi_{1}$, then $f_{1} \mathrm{~d}=\left(\varphi_{1}\right) f_{1}$.

Similarly as the cost function $f_{2}$ is concerned. The controls can implement the following real-life situations related to the actual events in the deformation process of the set of technological choice:

increase or decrease in the total costs: $f_{2} \mathrm{~d}=w_{1} f_{2}$;

increase or decrease in the fixed costs: $f_{2} \mathrm{~d}=f_{2} \mathrm{p}+w_{2} f_{3}$;

increase or decrease in the variable costs: $f_{2} \mathrm{~d}=w_{3} f_{2} \mathrm{p}+f_{3}$;

various combinations of changes in costs.

Table 1. Parameters of functions of the model of the production program

\begin{tabular}{|c|c|c|c|c|c|}
\hline No. & Productdescription & $a$ & $b$ & \multicolumn{2}{|c|}{$q$} \\
\hline \multirow[t]{3}{*}{1} & & $f_{1} x_{1}$ & $a_{11}$ & $b_{11}$ & $q_{11}$ \\
\hline & Product1 & $f_{2} x_{1}$ & $a_{21}$ & $b_{21}$ & $q_{21}$ \\
\hline & & $f_{4} x_{1}$ & $a_{41}$ & $b_{41}$ & $q_{41}$ \\
\hline \multirow[t]{6}{*}{2} & & $f_{1} x_{2}$ & $a_{12}$ & $b_{12}$ & $q_{12}$ \\
\hline & Product 2 & $f_{2} x_{2}$ & $a_{22}$ & $b_{22}$ & $q_{22}$ \\
\hline & & $f_{4} x_{2}$ & $a_{11}$ & $b_{11}$ & $q_{11}$ \\
\hline & & $f_{1} x_{3}$ & ....... & $\ldots \ldots$. & ... \\
\hline & n.w. & $f_{2} x_{3}$ & ....... & n...... & ... \\
\hline & & $f_{4} x_{3}$ & $\ldots \ldots$ & & $\ldots$ \\
\hline \multirow[t]{3}{*}{$\mathrm{j}$} & & $f_{1} x_{\mathrm{j}}$ & $a_{1 \mathrm{j}}$ & $b_{1 \mathrm{j}}$ & $q_{1 \mathrm{j}}$ \\
\hline & Product $i$ & $f_{2} x_{\mathrm{i}}$ & $a_{2 \mathrm{j}}$ & $b_{2 \mathrm{j}}$ & $q_{2 \mathrm{i}}$ \\
\hline & & $f_{4} x_{\mathrm{j}}$ & $a_{4 \mathrm{j}}$ & $b_{4 \mathrm{j}}$ & $q_{4 \mathrm{j}}$ \\
\hline \multirow[t]{3}{*}{$\mathrm{J}$} & & $f_{1} x_{\mathrm{j}}$ & $a_{1 \mathrm{~J}}$ & $b_{1 \mathrm{~J}}$ & $q_{1 \mathrm{~J}}$ \\
\hline & Product $j$ & $f_{2} x_{\mathrm{i}}$ & $a_{2 \mathrm{j}}$ & $b_{2 j}$ & $q_{2 \mathrm{i}}$ \\
\hline & & $f_{4} x_{\mathrm{J}}$ & $a_{4 \mathrm{j}}$ & $b_{4 \mathrm{j}}$ & $q_{4 \mathrm{j}}$ \\
\hline
\end{tabular}

After the formation of Table 1, using derived relations of functions of the model, the initial parameters of the production program have been calculated (see Figure 4). 


\begin{tabular}{|c|c|c|c|c|c|c|}
\hline \multirow{2}{*}{$\begin{array}{l}\text { Parameter } \\
\text { description }\end{array}$} & \multirow{2}{*}{ Units } & \multicolumn{5}{|c|}{ Products included in the production program } \\
\hline & & $X_{1}$ & $\ldots$ & $X_{j}$ & $\ldots$ & $X_{J}$ \\
\hline Capacity & $\begin{array}{c}\text { natural } \\
\text { units }\end{array}$ & & $\cdots$ & & & \\
\hline $\begin{array}{c}\text { Maximum } \\
\text { output }\end{array}$ & $\begin{array}{c}\text { natural } \\
\text { units }\end{array}$ & & $\cdots$ & & & \\
\hline $\begin{array}{l}\text { Demand } \\
\text { volume }\end{array}$ & $\begin{array}{l}\text { natural } \\
\text { units }\end{array}$ & & \multirow{5}{*}{$\begin{array}{l}\text { All parameters are calculated on the } \\
\text { basis of Table } 1 \text { and serve as initial } \\
\text { parameters and regulatory restrictions } \\
\text { in the calculation of the production } \\
\text { program. }\end{array}$} & & & \\
\hline Capacity cost & RUR & & & & & \\
\hline Demand cost & RUR & & & & & \\
\hline $\begin{array}{l}\text { Maximum } \\
\text { output cost }\end{array}$ & RUR & & & & & \\
\hline $\begin{array}{l}\text { Maximum } \\
\text { profit }\end{array}$ & RUR & & & & & \\
\hline $\begin{array}{l}\text { Production } \\
\text { profitability }\end{array}$ & per cent & & $\ldots$ & & & \\
\hline Invested capital & RUR & & $\ldots$ & & & \\
\hline
\end{tabular}

Figure 4. Initialcharacteristicparametersofproductsoftheproductionprogram

Limitation on profits:

$$
P v=\sum_{j}^{J} f_{4} X j=\sum_{j}^{J}\left(a_{4 j} x_{j}^{2}+b_{4 j} x_{j}-q_{4 j}\right)+\left(a_{4 j *}^{n} x_{j *}^{2}+b_{4 j *}^{n} x_{j *}-q_{4 j *}^{n}\right) \geq P_{v}^{n},(12)
$$

where $P_{v}^{n}$-means normative value of profits, $a_{4 j *}^{n}, b_{4 j *}^{n}, q_{4 j *^{-}}^{n}$ coefficients of the profit functions for a new product.

Intheequationf $_{4}$ we deliberately indicate the share of the profits generated from the production and sales of a new product, since it is necessary to show the impact on profit of excluded and implemented products, as well as the interaction between the total investment volume and the rate of the launch of new products.

Limitation on investments in OIP:

$$
\sum_{j}^{J}\left(a_{2 j} x_{j}^{2}+b_{2 j} x_{j}+q_{2 j}\right) \leq I_{0}
$$

where $I_{0}$ means a normative (planned) value investments in the production program, the left part of the equation (13) shows the total estimated investments in the production program.

The regulatory or given value of the total investment volume, as it has previously been shown, consists of two parts: investment allocated on production and innovations:

$$
I=I_{\mathrm{o}}+I_{n},
$$

The equation (14) can be written as follows:

$$
I=\lambda I+(1-\lambda) I
$$

$\lambda$ indicates the share of investments in production, while $(1-\lambda)$ indicates the share of investment in innovation, i.e.

$$
I_{\mathrm{o}}=\lambda I, I_{n}=(1-\lambda) I \text {. }
$$

Accounting for $\lambda$ in the structure of investment allows to use it as a control parameter in the OIP optimization.

The structure of investment is an important tool for optimizing the OIP, as it is aimed at both ensuring the current profitability, and the effective investment of the innovative program. In fact, the equations (15) and (16) 
determine the tactics of innovation investment in terms of time and volume, in particular, it can be presented in the tabular form, which shall specify the investment volume at the time intervals, for example, as shown in Table 2. It should be emphasized that the Table contains a hypothetical example, there can be another set of different parameters listed in the Table, however, it is obvious that this investment strategy defines the procedure for replacing an old product to a new one. Specifying the options as in Table 2 several options for replacing the product can be checked on the model.

Table 2. Example of the interaction of the time period, the investment volume and the replacement parameter

\begin{tabular}{lcccc}
\hline The time period & 2011 & 2012 & 2013 & 2014 \\
\hline Investmentvolume, millionRUR & 80 & 120 & 140 & 65 \\
Parameter of replacement of an old product $\alpha$ & 0 & 0 & 0.3 & 0.7 \\
\hline
\end{tabular}

The general algorithm for the modeling of operational and innovation program

1. On the basis of retrospective and analytical data of the enterprise we can form a file of life cycles of production of main products, if necessary the procedure for the aggregation of similar nomenclature items can be carried out.

2. Dependencies on the planning time of sales (demand) for each product, based on marketing data, can be combined in the tabular form, additionally including in it the standard deviation, also for each product. Obviously, the forecasting of the random variable of "demand" based on the life cycle curve is due to the presence of this value in the interval, for example, according to the equation (2).

3. For each product $\mathrm{j}$ we form the functions of costs and sales in accordance with Table 1 . If we present $\mathrm{fl}$, $\mathrm{f} 2, \mathrm{f} 4$ by linear functions, then for sales volume it is necessary to know the price of each product, for example on the basis of management accounting data, variable costs per output unitand fixed costs: in total for the program and for each product separately.

4. Demand forecast $G_{j}^{w}$ for productsj based on product life cycles shall be carried out on the basis of the Monte Carlo algorithm, and then for each product formedthe restrictions of the following type:

$$
\mathrm{Xj} \leq G_{j}^{w} \leq X_{j}^{m}
$$

for the optimization model of the production program. This intermediate restriction is necessary to account for the production capacity for each product: it suggests that the upper random forecasting limit $G_{j}^{w}$ should not exceed the production capacity for this product.

5. Carry out the calculation of the optimization model and determine the optimal program.

6. For the product being replaced $j^{*}$ should be formed the options for strategies of investment and replacement of $\mathrm{j}$ on $\mathrm{j}^{*}$. The options for strategies are conditioned by the investment volume and rate, the nature of the investment in stages of the innovation process, the rate of production growth up to the project level and the payback period, for example, uniform investment at all stages; investing in large quantities in the early stages; investments in new technologies and organization of production, i.e. improving the innovation capacity, etc. The replacement strategy consists of two vectors, the elements of the first vector show the volume of investments for each year up to the year of the start of mass production and further for each year the projected production volume of a new product; second vector shows a mechanism for replacement of an "old" products on a "new" one in accordance with equations (3), (4).

7. For each option of the replacement of a product on a new one (similar to the investment project) we calculate NPV. If NPV $=0$, we define the proposed the period of expected project payback on the launch of a new product, which is included in this option of the strategy for the evaluation of the initial investment In.

8. The source of financing (covering) In is a part of fixed costs of the enterprise. The total amount of investment in innovation is distributed for the years in accordance with an option of the replacement strategy (Clause 5) of this algorithm, so that

$$
I_{n}=\sum_{t=1}^{T}\left(1-\lambda_{t}\right) I
$$

at the same time we have previously shown that I - is the amount of investment in OIP, in the optimization model it serves as the right part of restrictions on the volume of investment in the entire program of current production and innovations. The mechanism of the ratio is as follows: the volume of innovation investment for the 
following yearInt +1 is formed due to the undistributed profit for preceding year $t$ and general fixed costs.

9. Then turn to the calculation of the financial parameters and indicators, as well as the parameters of sustainable growth.

10. Paragraphs 6 and 8 shall be repeated for all options of replacement strategies.

11. Select the version of the decision that is the most satisfactory in cost and time criteria.

\section{Conclusion}

Thus, as a result of the study implemented a systematic formulation of the general task of the formation of operational and innovation program, designed to optimize under different criteria the process of resource usage, including: investment, financial, technological, production and information capabilities of the corporation. There have also been solved the problem of the construction of the model used for planning innovations from the point of view of investment strategies and optimization of launch of new products on the market and maximize the rents.

The optimization task allows to evaluate the effectiveness of not only the investment projects, innovations, but also any other organizational and technical measures aimed at changing the technical, economic and financial indicators, achievement of their expected values.

The solution of the given problem of planning the activities of the enterprise for the future can be regarded as the optimization of planning the operational and innovation activities of the enterprise, technical, economic and financial planning, the analysis of the financial and economic state of the enterprise over time, based on all the main indicators in and outside this model.

Such a problem is important for research on the development of a methodology for sustainable development of the enterprise, as well as for the practice of its management. Consistency in the technical, economic and financial management of the company allows to justify the prospect of its development, economically evaluate the options for such a development, justify the value of the stochastic reserve of sales volume, profits and other strategic indicators in order to ensure the performance of the key planned indicators.

\section{References}

Bogoviz, A., \& Mezhov, S. (2014). Innovation Processes in the Russian Economy: problems and development trends. Economics of Sustainable Development, 2(18), 21-28.

Boutellier, R. (2008). Managing Global Innovation, Uncovering the Secrets of Future Competitiveness (3rd ed.). Berlin. Springer.

Chesbrough, H. (2006). Open Innovation: Researching a New Paradigm. Oxford: Oxford University Press.

Cooper, R., \& Edgett, S. (2006). Stage-Gate and the critical success factors for new product development. BP Trends, July.

Danilin, V. (2006). Operating and financial planning in corporations (methods and models).Moscow. Science.

Gassmann, O. (2006). Opening up the innovation process: towards an agenda. $R \& D$ Management, 36(3), 223-226. http://dx.doi.org/10.1111/j.1467-9310.2006.00437.x

Higgins, R. (1998). Analysis for Financial Management (5th ed.). Irwin.

Kondratiev, V. (2003). Corporate governance and investment process. Moscow: Science.

Mezhov, S. (2012). Economy of the innovation corporation: Theory and problems of efficiency. Barnaul: Publishing House AAEP.

Mezhov, S. (2014). Operational and innovative processes of corporations: the paradigm of planning and efficiency assessment. Bulletin "AAEP", Barnaul, 2(34), 54-57.

Mezhov, S. (2011). Some approaches to solution of the problems of organization of mass innovative production. Innovations, 6(152), 118-123.

Mezhov, S. (2014). Theoretical and Methodological Bases of Forming the Operational and Innovation Program of the Company Advances.Natural and Applied Sciences, 8(5), 451-457.

Pleschinsky, A. (2004). Optimization of inter-firm interactions and intra-firm management decisions. Moscow: Science, Series "Economics of the modern Russia".

Prahalad, C. (1996). Competing for the future. Harvard Business School Press. 
Ragulina, Y. (2014). Malyshkov, V. The Entrepreneurial Climate in Russia: The Present and the Future. Life Science Journal, 11(6s).

Sobolev, V. (2000). Modeling and optimization in managing the development of large economic systems (the full product life cycle). Novosibirsk: NGAEU.

Titov, V. (2007). Optimization of industrial corporation management: methodology and modeling issues. Novosibirsk: IEOPP SB RAS.

Titov, V., \& Mezhov, S. (2013). A model of operational and innovative program of industrial enterprise. Improving the institutional management mechanisms in industrial corporations, edited by Titov, V. V. \& Markova, V. D. Novosibirsk: PublishingHouse "IEOPPSBRAS".

Van Horne, J. (2009). Fundamentals of Financial Management (13th ed.). Prentice Hall.

\section{Copyrights}

Copyright for this article is retained by the author(s), with first publication rights granted to the journal.

This is an open-access article distributed under the terms and conditions of the Creative Commons Attribution license (http://creativecommons.org/licenses/by/3.0/). 